\title{
THE EFFECTS OF INTRAVENOUSLY ADMINISTERED AMINOPHYLLINE ON CEREBRAL CIRCULATION AND METABOLISM IN MAN ${ }^{2}$
}

\author{
BY RICHARD L. WECHSLER, LEE M. KLEISS, AND SEYMOUR S. KETY \\ (From the Department of Physiology and Pharmacology, Graduate School of Medicine, Uni- \\ versity of Pennsylvania, Philadelphia, and the Surgical Services, Hospital of the \\ University of Pennsylvania)
}

(Received for publication July 21, 1949)

There is a widely held belief that aminophylline, in addition to its effect on bronchioles, kidneys and heart, also exerts a stimulating effect on central nervous function and improves the cerebral circulation $(1,2)$. Experimental evidence for this belief is difficult to find. Practically none has been reported in humans and very little in animals. Dumke and Schmidt (3) demonstrated that the cerebral vessels are dilated by the intra-arterial injection of aminophylline in the anesthetized macacque monkey. Intravenous aminophylline, on the other hand, increased cerebral blood flow in two monkeys and decreased it in another two. Thus, the cerebral actions of aminophylline as it is used clinically are not clearly defined and it seemed of interest, therefore, to study the effects on the cerebral circulation and metabolism in man.

\section{METHODS}

Ten hospitalized patients, without any obvious cerebral depression, were chosen at random. There were six females and four males varying in age from 14 to 69 years. A cerebral blood flow (CBF) was performed by means of the nitrous oxide method (4). This was called the control flow (C). Following this, $0.5 \mathrm{G}$. of aminophylline in $250 \mathrm{cc}$. of physiological saline solution were administered intravenously over a period of 20 minutes. While the last $50 \mathrm{cc}$. ran in, a second or experimental cerebral blood flow (E) was performed. Pulse, mean arterial blood pressure (MABP), obtained directly from the femoral artery by means of a damped mercury manometer, and respiratory rates were recorded before and during each flow. Cerebral metabolic rate in terms of cerebral $\mathrm{O}_{2}$ consumption $\left(\mathrm{CMR}_{\mathrm{O}_{2}}\right)$ and cerebrovascular resistance (CVR) were calculated as previously described (4).

Blood gas analyses were made with the Van SlykeNeill manometric apparatus (5). Measurement of blood $\mathrm{pH}$ was made anaerobically at $37 \circ \mathrm{C}$. by means of a glass electrode and a Cambridge potentiometer. Values for

1 This investigation was supported (in part) by a research grant from the Division of Research Grants and Fellowships of the National Institutes of Health, U. S. Public Health Service. blood carbon dioxide tension were calculated by means of the nomograms presented by Peters and Van Slyke (5).

\section{RESULTS}

The data obtained in these studies are presented in Tables I and II. The most striking result was a statistically significant decrease in cerebral blood flow from a mean of 59.4 to $44.4 \mathrm{cc} . / 100 \mathrm{G}$./ min. $(p<.01)$. This decrease in CBF was due to a highly significant increase in cerebrovascular resistance from 1.7 to $2.1 \mathrm{~mm}$. $\mathrm{Hg}(\mathrm{p}<.001)$. An expected increase in respiration occurred, reflected in a decrease in arterial $\mathrm{CO}_{2}$ tension and an increase in arterial $\mathrm{pH}$. There was no significant change in arterial $\mathrm{O}_{2}$ content, MABP or cerebral metabolism in the group as a whole. As a result of the decrease in $\mathrm{CBF}$ and the constant cerebral $\mathrm{O}_{2}$ utilization, the internal jugular $\mathrm{O}_{2}$ content decreased from 8.2 to 6.2 vols. $\%$ ( $\mathrm{p}<$ $.001)$ and the cerebral arteriovenous $\mathrm{O}_{2}$ difference increased from 6.7 to 8.7 vols. $\%(\mathrm{p}<.01)$. The internal jugular $\mathrm{CO}_{2}$ content, $\mathrm{pH}$ and $\mathrm{CO}_{2}$ tension remained constant.

The high values obtained for the control cerebral blood flow (mean of 59.4 compared to a normal mean of $51 \mathrm{cc} . / 100 \mathrm{G} . / \mathrm{min}$.) were probably due to the presence of anemia in several of these unselected hospital patients. This is shown by the mean hematocrit of $38 \%$.

\section{DISCUSSION}

The mechanism for these changes is not immediately apparent. It is possible that aminophylline stimulates respiration leading to hyperventilation with a low arterial $\mathrm{CO}_{2}$ tension. Since $\mathrm{CO}_{2}$ is a known dilator of cerebral vessels, the decrease in arterial $\mathrm{CO}_{2}$ tension causes cerebral vasoconstriction with consequent increase in cerebrovascular resistance and decrease in cerebral blood flow (6). However, the decrease in arterial 
TABLE I

Effects of aminophylline on blood gases

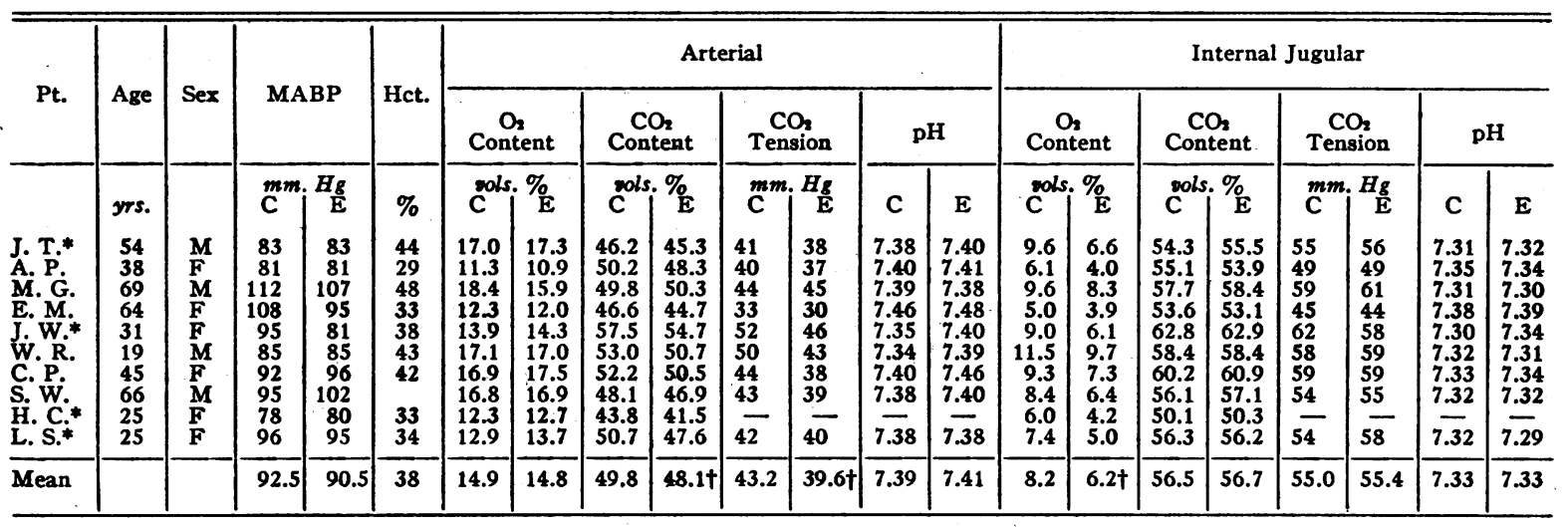

* These patients showed subjective reactions to aminophylline.

$\dagger$ Indicates statistically significant change $(p<0.01)$.

C = Control Flow.

$\mathrm{E}=$ Experimental Flow following aminophylline.

TABLE II

Effects of aminophylline on cerebral function

\begin{tabular}{|c|c|c|c|c|c|c|c|c|}
\hline \multirow{2}{*}{ Pt. } & \multicolumn{8}{|c|}{ Cerebral } \\
\hline & \multicolumn{2}{|r|}{$A-V_{O_{2}}$} & \multicolumn{2}{|c|}{$\mathrm{CBF}$} & \multicolumn{2}{|c|}{$\mathrm{CMR}_{\mathrm{O}_{2}}$} & \multicolumn{2}{|c|}{ CVR } \\
\hline $\begin{array}{l}\text { J. T.* } \\
\text { A. P. } \\
\text { M. G. } \\
\text { E. M. } \\
\text { J. W.* } \\
\text { W. R. } \\
\text { C. P. } \\
\text { S. W. } \\
\text { H. C. } \\
\text { L. S.* }\end{array}$ & $\begin{array}{c}C \\
7.4 \\
5.2 \\
8.8 \\
7.3 \\
4.9 \\
5.6 \\
7.6 \\
8.4 \\
6.3 \\
5.5\end{array}$ & \begin{tabular}{|rr} 
ools. \% & E \\
& 10.7 \\
& 6.9 \\
7.6 \\
8.1 \\
8.2 \\
7.3 \\
10.2 \\
10.5 \\
8.5 \\
8.7
\end{tabular} & $\begin{array}{l}c^{c c . /} \\
44 \\
73 \\
46 \\
46 \\
80 \\
81 \\
52 \\
44 \\
59 \\
69\end{array}$ & $\begin{array}{r}\text { E } \\
39 \\
47 \\
42 \\
39 \\
54 \\
43 \\
32 \\
35 \\
51 \\
62\end{array}$ & $\begin{array}{l}c^{c c} \\
3.2 \\
3.8 \\
4.0 \\
3.4 \\
3.9 \\
4.5 \\
4.0 \\
3.7 \\
3.7 \\
3.8\end{array}$ & $\begin{array}{l}\text { in. } \\
\\
4.2 \\
3.6 \\
3.2 \\
3.2 \\
4.4 \\
3.2 \\
3.2 \\
3.7 \\
4.3 \\
5.4\end{array}$ & $\begin{array}{c}c^{c} \\
\text { c } \\
1.9 \\
1.1 \\
2.5 \\
2.3 \\
1.2 \\
1.1 \\
1.8 \\
2.2 \\
1.3 \\
1.4\end{array}$ & $\begin{array}{l}\text { in. } \\
\text { E } \\
2.1 \\
1.7 \\
2.6 \\
2.4 \\
1.5 \\
1.9 \\
3.1 \\
2.9 \\
1.6 \\
1.5\end{array}$ \\
\hline Mean & 6.7 & $8.7 \dagger$ & 59.4 & $44.4 \dagger$ & 3.8 & 3.8 & 1.7 & $2.1 \dagger$ \\
\hline
\end{tabular}

* These patients showed subjective reactions to aminophylline.

t Indicates statistically significant change $(p<0.01)$.

$\mathrm{C}=$ Control Flow.

$\mathbf{E}=$ Experimental Flow following aminophylline.

$\mathrm{CO}_{2}$ tension is probably not large enough to produce the decrease in cerebral blood flow observed after aminophylline. From observations during voluntary hyperventilation (6) it appears that a decrease in arterial $\mathrm{pCO}_{2}$ of greater magnitude would be necessary to produce the degree of cerebral vasoconstriction which occurred with aminophylline.

It is perhaps more probable that aminophylline constricts the cerebral vessels and thus causes the decrease in cerebral blood flow. With the decrease in cerebral flow, $\mathrm{CO}_{2}$ tension of the brain would be expected to increase. Since increased $\mathrm{CO}_{2}$ tension is a known respiratory stimulant, it may be postulated that the cause of the hyperventilation resides in the diminished cerebral blood flow. This hyperventilation diminishes the arterial $\mathrm{CO}_{2}$ tension and results in a drop of the brain and internal jugular $\mathrm{CO}_{2}$ tension to its previous level.

With the decrease in cerebral blood flow however achieved, and a constant overall $\mathrm{O}_{2}$ consumption, the internal jugular $\mathrm{O}_{2}$ content, of course, 
falls. Since the internal jugular $\mathrm{O}_{2}$ content is a reflection of the brain $\mathrm{O}_{2}$ content, aminophylline causes anoxia of cerebral tissue.

The decrease in cerebral blood flow following aminophylline is compatible with the observations of Greene, Paul and Feller (7) that this drug decreases cerebrospinal fluid pressure. Other compatible results are those of Gibbs and his associates (8) who found that $0.5 \mathrm{G}$. caffeine sodium benzoate injected intravenously resulted in a drop in cerebral blood flow as measured qualitatively by a thermoelectric flow recorder. Caffeine has been shown to decrease cerebrospinal fluid pressure $(9,10)$. As a result of independent spinal fluid pressure and cerebral blood flow studies with high and low $\mathrm{CO}_{2}$ tensions $(6,11)$, and with histamine (12) it is now apparent that cerebral vasoconstriction decreases cerebrospinal fluid pressure while vasodilation tends to raise it.

It was noted that four of the patients reacted to the drug with extreme anxiety associated with symptoms such as tachycardia, palpitation, dizziness, sweating, weakness, nausea, an intense desire to void, and a drop in blood pressure. Each of these four cases had an increase in cerebral $\mathrm{O}_{2}$ consumption (see Table II), the mean showing a statistically significant rise from 3.7 to $4.6 \mathrm{cc}$. $/ 100$ G./min. None of the other six patients showed an increase in $\mathrm{CMR}_{\mathbf{O}_{3}}$. These six had a statistically significant decrease in cerebral $\mathrm{O}_{2}$ consumption from 3.9 to $3.3 \mathrm{cc} . / 100 \mathrm{G}$. $/ \mathrm{min}$.

In those patients who experienced anxiety and an increase in cerebral metabolism, aminophylline may primarily have caused the associated symptoms by its effect on the heart, blood pressure or kidneys. These symptoms may then have caused the anxiety which in turn could have led to the increase in cerebral metabolism. It is equally possible that aminophylline may have increased cerebral metabolism and that this primary increase resulted in the anxiety and some of the associated symptoms.

\section{SUMMARY}

1. The effects of administration of clinically therapeutic doses of aminophylline were studied on the blood gases, blood $\mathrm{pH}$, cerebral blood flow, cerebral $\mathrm{O}_{2}$ consumption, and cerebrovascular resistance in ten hospitalized patients without any obvious cerebral depression.

2. In these cases aminophylline produced a marked constriction of cerebral vessels and a real anoxia of cerebral tissue.

3. Some patients react to the drug with pronounced anxiety associated with disturbing symptoms and an increase in cerebral $\mathrm{O}_{2}$ consumption.

\section{BIBLIOGRAPHY}

1. Goodman, L., and Gilman, A., Pharmacological Basis of Therapeutics. Macmillan Company, New York, 1941, p. 279.

2. Sollmann, T. H., Manual of Pharmacology. W. B. Saunders Co., Philadelphia, 1948, Ed. 7, p. 213-226.

3. Dumke, P. R., and Schmidt, C. F., Quantitative measurements of cerebral blood flow in the macacque monkey. Am. J. Physiol., 1943, 138, 421.

4. Kety, S. S., and Schmidt, C. F., The nitrous oxide method for the quantitative determinations of cerebral blood flow in man; theory, procedure, and normal values. J. Clin. Invest., 1948, 27, 476.

5. Peters, J. A., and Van Slyke, D. D., Quantitative Clinical Chemistry. Williams \& Wilkins, Baltimore, 1931.

6. Kety, S. S., and Schmidt, C. F., The effects of altered arterial tensions of carbon dioxide and oxygen on cerebral blood flow and cerebral oxygen consumption of normal young men. J. Clin. Invest., 1948, 27, 484.

7. Greene, J. A., Paul, W. D., and Feller, A. E., The action of theophylline with ethylenediamine on intrathecal and venous pressures in cardiac failure and on bronchial constriction in cardiac failure and in bronchial asthma. J. A. M. A., 1937, 109, 1712.

8. Gibbs, F. A., Gibbs, E. L., and Lennox, W. G., The cerebral blood flow in man as influenced by adrenalin, caffeine, amyl nitrite and histamine. Am. Heart J., 1935, 10, 916.

9. Denker, P. G., The effect of caffein on the cerebrospinal fluid pressure. Am. J. M. Sc., 1931, 181, 675.

10. Loman, J., and Myerson, A., The action of certain drugs on the cerebrospinal fluid and on the internal jugular venous and systemic arterial pressures of man. Arch. Neurol. \& Psychiat., 1932, 27, 1226.

11. Cobb, S., and Fremont-Smith, F., The cerebral circulation. XVI. Changes in the human retinal circulation and in the pressure of cerebrospinal fluid during inhalation of a mixture of carbon dioxide and oxygen. Arch. Neurol. \& Psychiat., 1931, 26, 731.

12. Shenkin, H., To be published. 